\title{
EFEITO DAS AUXINAS ÁCIDO INDOLBUTÍRICO (AIB), ÁCIDO INDOLACÉTICO (AIA) E ÁCIDO NAFTALENOACÉTICO (ANA) NO ENRAIZAMENTO in vitro DE Myracrodruon urundeuva FR. ALL.
}

\author{
Rosembrando S. L. Carvalho Filho'; Tecla dos Santos Silva ${ }^{2}$; Thaylane Carneiro \\ Rocha $^{3}$ José Raniere Ferreira de Santana ${ }^{4}$ \\ 1. Bolsista PIBIC/CNPq, Graduando em Agronomia, Universidade Estadual de Feira de Santana, Laboratório de Cultura de \\ Tecidos Vegetais, Unidade Experimental Horto Florestal, e-mail: carvalhoea@yahoo.com \\ 2. Bióloga, MSc. em Biotecnologia, Doutoranda em Recursos Genéticos Vegetais, Universidade Estadual de Feira de \\ Santana, Laboratório de Cultura de Tecidos Vegetais, Unidade Experimental Horto Florestal, e-mail: silva.stecla@gmail.com \\ 3. Graduanda em Agronomia, Universidade Estadual de Feira de Santana, Laboratório de Cultura de Tecidos Vegetais, \\ Unidade Experimental Horto Florestal, e-mail: thaylane.car@ hotmail.com \\ 4. Orientador, Departamento de Ciências Biológicas, Universidade Estadual de Feira de Santana e-mail: raniere@ uefs.br
}

PALAVRAS-CHAVE: aroeira-do-sertão; enraizamento; micropropagação.

\section{INTRODUÇÃO}

A aroeira-do-sertão (Myracrodruon urundeuva Fr. All.) é uma árvore pertencente à família Anacardiaceae que apresenta distribuição natural limitada à América do sul sendo encontrada em formações vegetais de caatinga, cerrado e floresta pluvial (LORENZI; MATOS, 2002). A espécie possui madeira de coloração pardo-avermelhada, muito dura e imputrescível, sendo bastante utilizada para obras externas e construção civil (LORENZI, 1998).

Além das características já mencionadas, a aroeira-do-sertão possui ainda uso medicinal, sendo empregada no tratamento de hemorragias, infecções respiratórias, urinárias e distúrbios no sistema digestório (MATOS, 1999). Em virtude dos múltiplos usos destinados à M. urundeuva, esta vem passando por um processo de exploração intensa, de forma predatória, causando a devastação de suas populações naturais (BRANDÃO, 2000), sendo, portanto, considerada uma espécie ameaçada de extinção (MMA, 2008). A cultura de tecidos vegetais possui um papel importante na preservação e multiplicação de espécies que estejam em vias de extinção, sendo a micropropagação uma via que proporciona a obtenção de um número elevado de mudas com estabilidade genética e qualidade fitossanitária, em curto espaço de tempo e em qualquer época do ano.

O enraizamento é uma das fases mais difíceis da micropropagação, sendo influenciada pelo meio de cultura, auxinas e suas concentrações (LEITZKE et al. 2009). Para Costa et al. (2008) esta etapa é fundamental, pois a obtenção de um sistema radicular funcional e uniforme é requisito básico para alcançar elevadas taxas de sobrevivência na fase da aclimatização. Nesse sentindo, o presente estudo teve como objetivo avaliar o efeito de diferentes concentrações das auxinas ácido indolbutírico (AIB), ácido indolacético (AIA) e ácido $\alpha$-naftalenoacético (ANA) no enraizamento in vitro de $M$. urundeuva.

\section{METODOLOGIA}

Foram utilizados brotos $( \pm 10-15 \mathrm{~mm})$ com 45 dias de idade induzidos a partir de segmentos nodais oriundos de plantas com 60 dias de idade e inoculados em tubos de em meio de cultura WPM (LLOYD \& McCOWN, 1980) suplementado com 8,0 $\mu \mathrm{M}$ de BAP (benzilaminopurina) e $10 \mu \mathrm{M}$ de AgNO3 (Nitrato de Prata). Os brotos foram inoculados em meio WPM, suplementado com distintas concentrações $(0,0 ; 2,0 ; 4,0 ; 6,0$ e $8,0 \mu \mathrm{M})$ das auxinas AIB ou AIA ou ANA isoladamente, com $87,64 \mathrm{mM}$ de sacarose e solidificado com 7 g.L-1 de ágar. O delineamento experimental foi inteiramente casualizado (DIC), com arranjo fatorial 3 x 5 (tipos de auxinas x concentrações de auxinas), totalizando 15 tratamentos com 5 repetições, cada uma composta por 5 parcelas (tubos de ensaio). $\mathrm{O} \mathrm{pH}$ do meio de cultura foi ajustado para $5,7 \pm 0,1$ (utilizando-se $\mathrm{NaOH}$ ou $\mathrm{HCl} 0,1 \mathrm{~N}$ ) antes da autoclavagem à 
temperatura de $121^{\circ} \mathrm{C}$ por 15 minutos. As culturas foram mantidas em sala de crescimento com temperatura de $25 \pm 3^{\circ} \mathrm{C}$, fotoperíodo de 16 horas e radiação fotossintética ativa de 60 $\mu \mathrm{mol} \mathrm{m}-2 \mathrm{~s}-1$.

Aos 45 dias foram avaliadas: porcentagem de explantes responsivos para formação de raízes (\%ERFR), o número de raízes (NR), matéria seca das raízes (MSR) (mg) e porcentagem de explantes que formaram calos (\%FC). Os dados foram avaliados estatisticamente, mediante a análise de variância, testando-se as médias pelo Teste de Tukey e através de Regressão, para os fatores qualitativos (e ajustes) e quantitativos, respectivamente. A análise estatística foi feita através do programa SISVAR, desenvolvido pela Universidade Estadual de Lavras (UFLA) (FERREIRA, 2011).

\section{RESULTADOS E DISCUSSÃO}

A análise de variância demonstrou efeito altamente significativo $(\mathrm{p}<0,01)$ da interação entre os fatores "AUXINA X CONCENTRAÇÃO” para as variáveis \%ERFR e NR, e efeito significativo $(\mathrm{p}<0,05)$ para a MSR e \%FC.

Ao analisar a variável \%ERFR obteve-se comportamento linear crescente $(p<0,01)$ com a utilização da auxina AIB, na qual à medida em que as concentrações dessa auxina foram aumentando, houve simultâneo aumento da taxa de explantes que formaram raízes (Figura 1A). Para as demais auxinas não foi possível o ajuste de um modelo matemático com significado biológico. Os resultados obtidos demonstraram efeito positivo do uso da auxina para a formação de raízes, mostrando a eficiência no uso do AIB em detrimento dos outros tipos de auxina (AIA e ANA) utilizados. Melo et al. (2001) afirmam que a utilização da auxina AIB para o enraizamento de lenhosas in vitro é amplamente aplicada devido a sua maior eficiência em diferentes espécies, além da menor fitotoxidez.

Para a variável NR, constatou-se comportamento linear crescente $(p>0,01)$ com a utilização da auxina AIB. Para o uso das demais auxinas testadas (ANA e AIA), não obtevese equação representativa (Figura 1B). Os resultados obtidos neste estudo concordam com Radmann et al. (2002) em culturas Malus domestica, na qual também avaliando diferentes tipos e concentrações de auxinas, em condições de presença e ausência de luz, os autores verificaram que a auxina AIB também induziu maior número de raízes.

Ao avaliar a variável matéria seca das raízes, obteve-se comportamento quadrático ascendente $(\mathrm{p}<0,01)$ na utilização da auxina ANA e linear crescente $(\mathrm{p}<0,01)$ quando o meio de cultura foi suplementado com AIB, onde ao aumentar a concentração dessa auxina houve aumento da quantidade de matéria seca produzida (Figura 1C). Para a auxina AIA, não foi possível a adequação de modelo matemático significativo. A curva de resposta com o uso de ANA indica que a produção máxima de matéria seca $(6,71 \mathrm{mg})$ é atingida no valor calculado de 4,39 $\mu \mathrm{M}$ dessa auxina. Fisiologicamente, as auxinas são responsáveis pelo aumento da divisão celular, expansão e alongamento celular, principalmente das células de caules e raízes que se expandem quase inteiramente por alongamento (KERBAUY, 2008). As diferenças nas respostas de desenvolvimento podem estar relacionadas com o estádio fisiológico de cada espécie utilizada e, sendo assim, o sucesso na indução de raízes depende do uso de concentrações adequadas dos reguladores e da utilização de tecidos ou células aptas a receberem estes estímulos (SOUTO et al. 2010). 


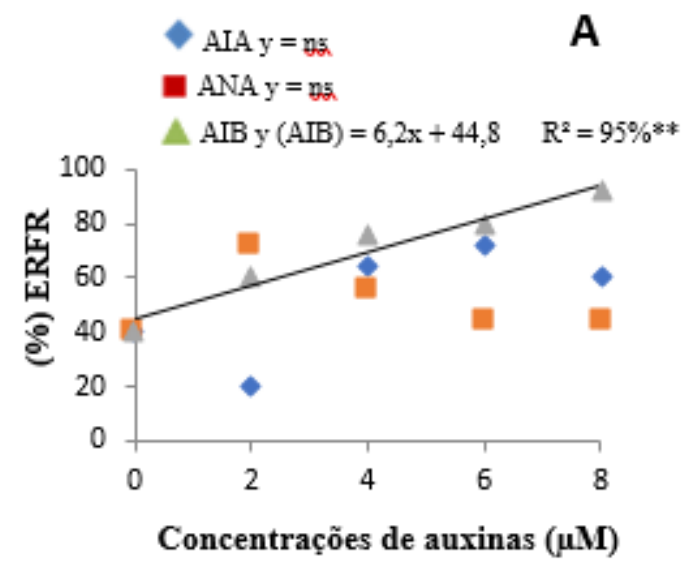

C

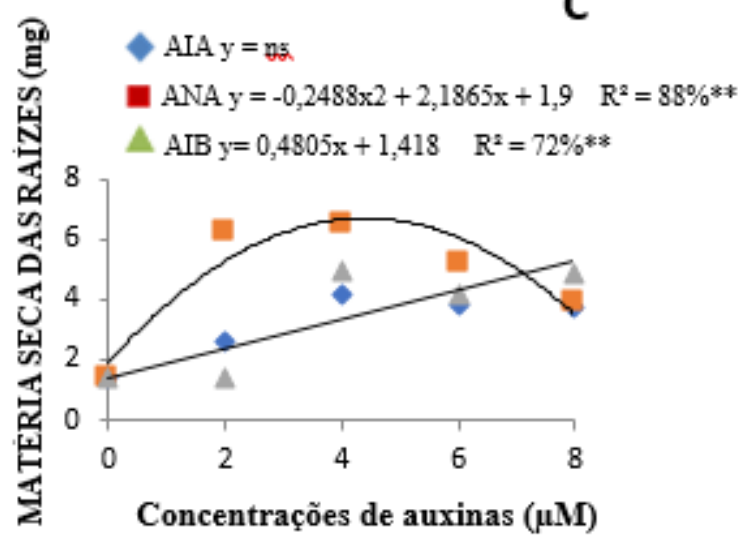

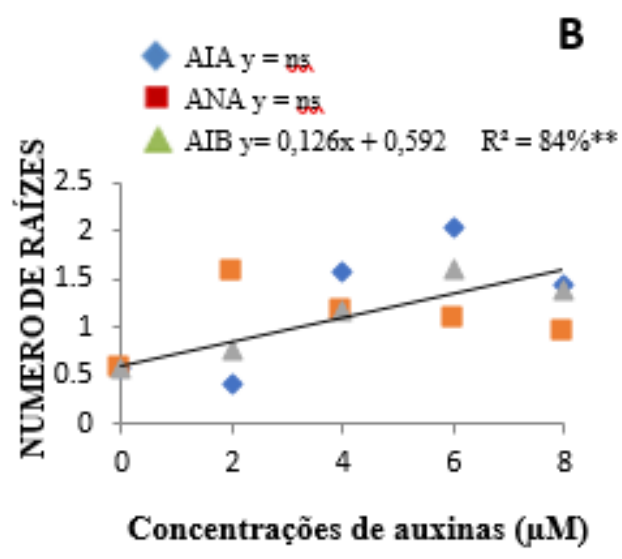

D

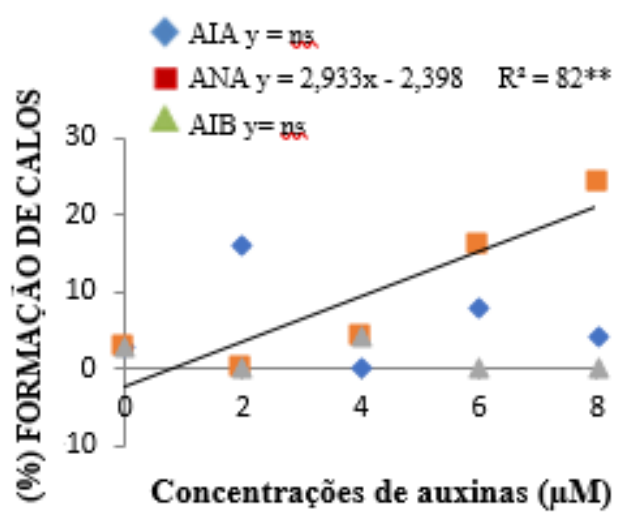

Figura 1: Porcentagem de explantes responsivos para formação de raízes (\%ERFR) (A), número de raízes $(\mathrm{B})$, matéria seca das raízes $(\mathrm{C})$ e porcentagem de formação de calos (D) obtidos a partir de brotos de Myracrodruon urundeuva aos 45 dias, inoculados em meio com diferentes concentrações $(0,0 ; 2,0 ; 4,0 ; 6,0$ e $8,0 \mu \mathrm{M})$ das auxinas AIA, ANA e AIB $\left({ }^{\text {ns, }{ }^{* *}}\right.$ Não significativo e significativo ao nível de $1 \%$ de probabilidade pelo teste $\mathrm{F}$, respectivamente). Feira de Santana, BA. 2017.

Ao estudar a \%FC, foi registrado comportamento linear crescente $(p<0,01)$ na utilização da auxina ANA. Já quando se utilizou AIA e AIB não foi obtida equação significativa (Figura 1D). A formação de calos na zona de enraizamento é dispensável, uma vez que afeta a qualidade das raízes e compromete a rizogênese de modo geral no que se refere a conexão vascular com a planta (ERIG et al. 2004). Lopes et al. (2001) sugerem que a formação de calos está diretamente relacionada com as concentrações endógenas de AIA. No que diz respeito a este trabalho, verifica-se o aumento da porcentagem de formação de calos com o aumento das concentrações de ANA, evidenciando um provável desequilíbrio de concentrações entre a auxina produzida pela planta e a auxina disponível no meio. 


\section{CONCLUSÃO}

O uso de $8,0 \mu \mathrm{M}$ de AIB, é indicada para o enraizamento in vitro de $M$. urundeuva. No entanto, em virtude do baixo número de plantas enraizadas, sugere-se novos estudos afim de aumentar essa taxa.

\section{REFERÊNCIAS}

BRANDÃO, M. Caatinga. In: MENDONÇA, M. P.; LINS, L. V. (Orgs). Lista vermelha das espécies ameaçadas de extinção da flora de Minas Gerais. Belo Horizonte: Fundação Biodiversitas e Fundação Zôo-Botânica de Belo Horizonte, p.75-85, 2000.

COSTA, S. H. F.; et al. Relação entre o tempo de enraizamento in vitro e o crescimento de plantas de bananeira na aclimatização. Revista Brasileira de Fruticultura. Jaboticabal v. 30, n.1, 2008.

ERIG, A. C.; SCHUCH, M. W.; CHAVES, A. C. Enraizamento in vitro e Aclimatização de mudas de Marmeleiro cvs. mc e adams, utilizadas como porta-enxerto para a Pereira. Scientia Agraria, v. 5, n. 1-2, p. 61-68, 2004.

FERREIRA, D. F. Sisvar: a computer statistical analysis system. Ciência e Agrotecnologia, Lavras, v. 35, n. 6, p. 1039-1042, 2011.

KERBAUY, G. B. Fisiologia Vegetal. 2.ed. Rio de Janeiro: Guanabara Koogan, 2008. p. 182-187. $470 \mathrm{p}$.

LEITZKE, N. L.; DAMIANI, R. C.; SCHUCH, W. M. Meio de cultura, concentração de AIB e tempo de cultivo no enraizamento in vitro de amoreira-preta e framboeseira. Revista Brasileira de Fruticultura. Jaboticabal-SP, v. 31, p. 582-587, 2009.

LOPES, S. C. et al. Enraizamento in vitro de Mogno (Swietenia macrophylla King). CERNE, v. 7, n. 1, p. 124-128, 2001.

LORENZI, H. Árvores brasileiras: Manual de Identficação e cultivo de plantas arbóreas nativas do Brasil. 2: ed. Nova Odessa: Editora Plantarum, 1998. 352 p.

LORENZI, H.; MATOS, F.J.A. Plantas medicinais no Brasil: nativas e exóticas cultivadas. Nova Odessa: Plantarum, 2002. 512p.

LLOYD, G.; McCOWN, B. Use of microculture for production and improvement of Rhododendron spp. HortScience, Alexandria, v. 15, 1980. p. 415.

MATOS, F. J. A. Plantas de medicina popular do Nordeste: propriedades atribuídas e confirmadas. Fortaleza: Edições UFC, 80p. 1999.

MMA, Ministério do Meio Ambiente. INSTRUÇÃO NORMATIVA No DE SETEMBRO DE 2008. Lista Oficial das Espécies da Flora Brasileira Ameaçadas de Extinção Disponível

<http://www.mma.gov.br/estruturas/ascom_boletins/_arquivos/83_19092008034949.pdf>

Data de Acesso: 26 de março de 2015.

MELO, B. et al. Efeitos de ANA e AIB in vitro no enraizamento e crescimento da parte aérea da plântula da guarirobeira [Syagrus oleracea (Mart.) Becc.]. Bioscience Journal. v. 17, n.1, p. 49-59, 2001.

RADMANN, E. B.; FACHINELlO, J. C.; PETERS, J. A. Efeito de Auxinas e Condições de Cultivo no Enraizamento in vitro de Porta-Enxertos de Macieira 'M-9'1. Revista Brasileira de Fruticultura, Jaboticabal - SP, v. 24, n. 3, p. 624-628, 2002.

SOUTO, J. S. et al. Efeitos do ácido naftalenoacético no desenvolvimento in vitro de Cattleya bicolor Lindl. (Orchidaceae), Revista brasileira de Biociencias, Porto Alegre, v. 8, n. 2, p. 179-185, 2010. 